\title{
The Nuts and Bolts of Teaching Implicatures in EFL/ESL Contexts: An Overview on the Role of Video-enhanced Input
}

\author{
Ali Derakhshan (Corresponding author) \\ English Language and Literature Department, Golestan University, Iran \\ E-mail: aderakhshanh@gmail.com \\ Hoda Mohsenzadeh \\ English Department, Kharazmi University, Iran \\ E-mail: Mohsenzadehn@yahoo.com \\ Saeid Mohammadzadeh \\ Faculty of Foreign Languages and Literature, Allameh Tabataba'i University, Iran \\ E-mail: saeid.mohammadzadeh@gmail.com
}

Received: 11-03-2014

doi:10.7575/aiac.ijalel.v.3n.5p.13
Accepted: 18-04-2014

Published: 01-09-2014

\begin{abstract}
The notion of implicature, the crucial role of which in second/foreign language learning has been repeatedly acknowledged by many scholars, is a key concept in Grice's ground-breaking theory of Cooperative Principle (CP). According to this theory, interlocutors of a conversation follow the four maxims of Quality, Quantity, Relevance and Manner or deliberately violate them in order to convey a message which is beyond what is directly said. This paper is an attempt to further the understanding of implicatures by spelling out the basic tenets of Grice's theory of implicatures and reporting the results of some of the studies conducted on this topic with a special emphasis on the role of videodriven prompts as influential sources of input. It finishes with new strands of research on implicatures.
\end{abstract}

Keywords: Cooperative Principle; Idiosyncratic-based Implicatures, Formulaic-based Implicatures

\section{Introduction}

Grice's well-known theory of Cooperative Principle, an established part of pragmatics, has been in the limelight for the last few decades. This theory which is based on the four maxims of Quality, Quantity, Relevance and Manner holds that the participants involved in a social interaction are expected to speak truthfully, sufficiently, relevantly and clearly. When one or more of these maxims are violated by the speaker, the listener understands that what the speaker intends to convey extends beyond the literal meaning of the words. This characteristic of the speaker's utterance through which what the speaker means goes far beyond what he exactly says is called "implicature". As many studies have evidenced, despite the ubiquity of implicatures in different aspects of everyday life, the understanding and conveyance of their implied meaning is a difficult task for the majority of EFL learners. The present paper intends to provide an overview on the trends and developments in the field of implicatures, to make sense of various studies that have been conducted on this topic and to bring to the fore their theories, their patterns of investigative procedures, and their findings.

\subsection{Conversational and Conventional Implicatures}

Grice (1975) posits that when the maxims of the Cooperative Principle are violated, as they often are, the addressee is called upon to derive what he calls "implicature" to reinstate it (Watts, 2003). Therefore, he makes a distinction between conventional and conversational implicature. Conventional implicature results in inferences hearers make based upon the conventional meanings being encoded as lexical items with no effect of context, e.g.,

(A) Where's Margaret this evening?

(B) She's either at a committee meeting or she's at home in Geneva. (Watts, 2003, p. 205)

Interlocutor B sounds to flout the Maxim of Quality since he does not know where Margaret is. If that is the case, interlocutor B should have simply said "I don't know", but this response might be interpreted as lack of cooperation. In order to perceive the meaning of this statement, contextual factors are not essential to be taken into consideration. Grice (1975) calls implicatures which can be derived on the basis of explicit linguistic evidence conventional implicatures. In contrast, if a speaker utters something which seems to be irrelevant to the interlocutor's preceding utterance, one or more maxims are violated. However, since the cooperative principle works at a somewhat deeper level, hearers will attempt to infer meaning from their interlocutor's utterance. Moreover, unlike conventional implicature, conversational implicature depends highly on contextual factors. Levinson (1983, p. 102) gives the following example:

A: Where's Bill?

B: There's a yellow VW outside Sue's house. 
Interlocutor B's utterance is apparently irrelevant to the question posed by interlocutor A and on the propositional level flaunts the maxims of relation and quantity. However, according to Grice's concept of conversational implicature, interlocutor A understands B's implied meaning based on their shared contextual knowledge that Bill owns a yellow VW. The concept of conversational implicature can thus also be used to explain why interlocutors are able to decode conventionally indirect utterances such as 'Can you pass me the book?' as a request to actually pass the book to the requester and not as a question about their physical ability to pass the book.

Grice's contribution was to offer an explicit and general account of implicature

.... distinction within the total signification of a remark...between what the speaker has said (in a certain favored and maybe in some degree artificial, sense of "said"), and what he has implicated (e.g., implied, indicated, suggested, etc.), taking into account the fact that what he has implicated may be either conventionally implicated (implicated by virtue of the meaning of some word or phrase which he has used) or non-conventionally implicated (in which case the specification of implicature falls outside the specification of the conventional meaning of the words used). (Grice, 1989, p.118)

In a nutshell, Grice's landmark expounds that in order to perceive the meaning of an utterance appropriate contextual knowledge is required. The fact that conversation is based on the cooperation of the interlocutors has made an important contribution to pragmatics (Leech, 1983). Although aspects of his work have been criticized, Levinson (1983) stated that 'the notion of conversational implicature is one of the single most important ideas in pragmatics' (p. 97).

\subsection{Different Classifications of Conversational Implicature}

Bouton (1994a) posits that conversational implicature is an inferential message or the process through which the speaker/writer and the listener/reader derive meaning. Bouton argues that the meaning of an utterance is perceived through inference in terms of the context, rather than through direct reference. Grice (1975) indicates that participants in a conversation expect whatever a speaker says to be trustful, appropriately informative, relevant, and clear, but at times speakers/writers choose not to abide by these principles and convey meaning indirectly. Bouton (1994a, 1994b) enumerates different classifications along with their examples for conversational implicature. Bouton (1999) makes a demarcation between idiosyncratic implicature and formulaic implicature. Idiosyncratic implicatures are those based on violations of Grice's relevance maxim. Formulaic implicatures, on the contrary, have typical structural or sematic features, such as POPE Q (Is the Pope Catholic?).

\subsubsection{Idiosyncratic Implicature Typology}

The idiosyncratic implicatures consist of four subtypes of implicature, namely Relevance-general, Relevanceevaluation, Relevance-disclosure, and Relevance-change. Detailed explanations regarding each type of implicature are illuminated below.

1.2.1.1 R-general: This type of implicature deals with responses that violate the relation maxim. The example clarifies more:

Situation: Lilly, Tom, and Tad are friends. One day, Lilly and Tom are talking about Tad.

Lilly: Where is Tad, Tom?

Tom: I think there's a red sports car parked over by Jenny's house?

\section{What is the point of Tom's question?}

(a) He just noticed that Jenny has bought a new red sports car.

(b) He has no idea about where Tad is.

(c) He thinks Tad may be at Jenny's house.

(d) He likes red sports car and wants Lilly to see one.

1.2.1.2 R-evaluation: This category is related to the responses which are given to evaluation.

Situation: Mary is a high school student who is taking a history class from Mr. Green. She recently turned in a term paper and she is curious to find out how she did. When she sees Mr. Green, she asks him about it.

Mary: Oh, Mr. Green, I'm really curious to find out how I did on my term paper. What did you think of it? Mr. Green: Well, that was a very difficult assignment.

\section{What does Mr. Green mean?}

(a) Mr. Green didn't like Mary's term paper very much.

(b) Mr. Green was just saying the assignment was difficult for many students.

(c) Mr. Green understood Mary must put much work into her paper.

(d) Mary did a good job because the assignment was very difficult. 
1.2.1.3 R- disclosure: This type deals with the responses to disclose oneself.

Situation: Beth ran into her old friend, Mike. She hadn't seen Mike for a while and wanted to catch up what was going on. Beth had heard that Mike was recently divorced and Beth asked Mike if this was true.

Beth: Did you just get divorced?

Mike: You know, I think we married too young.

\section{What does Mike mean?}

(a) Mike means that he did not get divorced.

(b) Mike regretted that he married so early.

(c) Mike means that he did get divorced.

(d) Mike and his wife don't match with each other.

$R$ - change: This category is related to the responses that totally change the topic.

Situation: Linda and Mike usually play golf on Saturdays. This Saturday, however, Mike went alone. When he returns, Linda wants to find out how well he did.

Linda: Hey, Mike. How did you do today at golf?

Mike: Man, umm. I'm sorry. I'm so tired of this cold weather.

\section{What does Mike mean?}

(a) He didn't play golf well today.

(b) He didn't go out to play golf, either.

(c) He felt bored because Linda didn't play with him.

(d) He was just complaining about the bad weather.

\subsubsection{Formulaic Implicature Typology}

Formulaic implicatures have typical structural or semantic features, such as Irony, Criticism, and POPE Q which are exemplified as follows:

\subsubsection{Irony}

Bouton (1988) posits that Irony is a violation of Quality Maxim (p.191).

Situation: At a recent party, there was a lot of singing and piano playing. At one point, Matt played the piano while Brain sang. Jill was not at the party, but her friend Linda was.

Jill: What did Brain sing?

Linda: I'm not sure, but Matt was playing "My wild Irish Rose".

\section{Which of the following is the closest to what Linda meant?}

(a) She was only interested in Matt and did not listen to Brian.

(b) She thought Brian sang badly.

(c) Matt and Brain were not doing the same song.

(d) She meant the song that Brian sang was "My Wild Irish Rose."

\subsubsection{Indirect Criticism through Implicature}

Situation: Two teachers, Mr. Jackson and Mrs. White, are talking about a student's term paper.

Mr. Jackson: Have you read Mark's term paper?

Mrs. White: Yes. I read it last night.

Mr. Jackson: How did you like it?

Mrs. White: I thought it was well-typed.

\section{How did Mrs. White like Mark's term paper?}

(a) She didn't like Mark's term paper.

(b) She liked the paper and she thought it was good.

(c) She thought it was surely well typed.

(d) She did like the form, but not the content. 
1.2.2.3 The POPE Q Implicature

It is the violation of Relevance Maxim based on the prototype dialog in which the apparently irrelevant question, Is the Pope Catholic? is given a response to another question to which the answer seems obvious (Bouton, 1988, p.191)

Situation: Two friends are talking about what they are going to do during summer.

Betty: My mother wants me to stay at home and entertain the relatives when they come to visit us at the beach. John: Do you have a lot of relatives?

Betty: Duh, does a dog have fleas?

What is the point of Betty's question?

(a) Betty thinks her relatives are boring.

(b) Betty does have a lot of relatives.

(c) Betty is asking John if a dog usually has fleas.

(d) Betty doesn't have many relatives.

While conversational implicature is part of everyday interaction, understanding implied meaning requires cultural knowledge and its interpretation can be difficult to L2 learners who have lived in the second-language context for several years (Bouton, 1994a, 1994b; Kasper \& Rose, 2002). Like manner, Keenan contends that the use of implicature in cross-cultural interaction is a potential barrier to effective communication (as cited in Bouton, 1994b, p.159). Studies, however, show that explicit classroom instruction can accelerate the learning of conversational implicature (Bouton, 1994a, 1999; Kubota, 1995).

\subsection{Teaching Conversational Implicatures}

Research has documented that conversational implicature in an L2 is mastered slowly unless it is explicitly taught and that formal instruction can facilitate the learning of most types of conversational implicature (Bouton, 1988, 1994a; Lee, 2002; Taguchi, 2002, 2009). Bouton (1994a) provides us with a procedure as how to address conversational implicature in an advanced ESL/EFL classroom:

1. Introduction of each type of implicature with the label, definition, and several examples for each;

2. Discussion of new examples of implicature:

- Identification of the implicature;

- Explanation of how literal meaning did not hold and how the implicature was detected;

- Identification of what is actually implied in the messages;

- Illustration of learners' experiences with implicature;

- Identification of similar implicatures in learners' L1s;

3. Group work creating dialogues containing implicature; and

4. Analysis of new examples of implicature provided by the teacher or by the learners (p.102).

Bouton (1994a) goes on to elaborate that the suggested interventional procedure above would take approximately six hours of instruction, which can be spread over several weeks. He recommends that after the instruction (steps 1-3) is implemented, step 4 could be drawn upon as an occasional warm-up of a regular class time. Learners take advantage of a discussion as to whom the appropriate recipients of a message with a given implicature would be, such as whether a message with a certain type of implicature tends to be more or less appropriate for higher-status or equal-status conversational partners.

\section{A Brief Review of the Empirical Studies on Implicatures}

Bouton (1988), considered as a pioneer in developing a test of implicature knowledge, investigated to what extent a person's cultural background affects his or her ability to derive the same meanings from conversational implicatures in English as native English-speaking Americans do, and whether a specially developed multiple-choice test measures a person's ability to interpret these implicatures. The results indicated that cultural background is a reliable predictor of nonnative speakers' (NNS) ability to interpret implicatures the way native speakers (NSs) do. It was also found that not only do NNSs derive different meanings from implicatures than NSs do, but culturally different NNSs also perform differently from each other. On par with Bouton (1988), Bouton (1994b) conducted a study to examine whether NNS learn to use implicature with little or no direct instruction. In this research it was found that there was a little meaningful correlation between the scores achieved on the IMPLC test and those on the English Placement Test (EPT) as a whole or on any of its three components.

Taguchi (2002) implemented relevance theory to second language research by measuring L2 learners' inferential ability to comprehend conversational implicatures. The analyses of verbal report protocols illustrated that lower proficiency students had similar access to inferential processes and they could trace relevance of the speaker's implied meaning based on context. Two of the common inferential strategies were reported to be paralinguistic cues and the rule of adjacency pair. Less proficient learners relied more on background knowledge and key word inferencing while proficient learners recognized more frequently the speaker's intended purpose of using an implicature. Finally, it was found that the learners in both groups successfully comprehended $70 \%$ or more of the implicature items, but higher proficiency students performed significantly better in their comprehension.

Garcia (2004) compared the pragmatic comprehension of low- and high-proficiency L2 English speakers by examining their ability to recognize indirect speech acts. The study focused on two types of implicatures test of pragmatic comprehension on 16 advanced and 19 beginning English language learners, namely specific implicatures 
and general implicatures. Garcia found that the high group significantly outperformed the low group on linguistic comprehension, pragmatic comprehension, comprehension of speech acts, and comprehension of conversational implicatures.

In the area of pragmatic comprehension, Roever (2005) compared ESL and EFL learners on three pragmatic constructs: comprehension of implicatures, comprehension of routines, and production of speech acts. There was a significant effect of residence abroad on the comprehension of routines, but it was found that there was no effect of context on the comprehension of implicatures and production of speech acts, although there was a significant L2 proficiency effect on both.

Taguchi (2009) explored the impact of proficiency on the comprehension of implicatures in L2 Japanese. It was reported that refusals were the easiest to comprehend, followed by conventional and non-conventional indirect opinions. As far as proficiency levels are concerned, all nonnative speakers comprehended refusals the best followed by conventional and non-conventional indirect opinions, but no difference was observed in native speakers' comprehension. The elementary students scored significantly poorer than advanced and intermediate students, but no difference was observed in comprehension speed across groups.

Taguchi (2011) investigated the effect of general proficiency and study-abroad experience on pragmatic comprehension in second-language English. In his study the analysis of the obtained scores indicated that there was a significant effect of proficiency on response times but no effect of study-abroad experience was observed. Comprehension accuracy scores unearthed mixed findings. It was fruitful for students to have study-abroad experience to comprehend nonconventional implicatures and routine expressions but not in indirect refusals.

Given that implicatures are a part of everyday interaction, and implied meaning requires cultural knowledge and its interpretation (Bouton, 1994a, 1994b; Kasper \& Rose, 2002), and given that textbook conversations do not provide sufficient pragmatic input and are not a reliable source of pragmatic input (Bardovi-Harlig, Hartford, Mahan-Taylor, Morgan, \& Reynold, 1991; Boxer \& Pickering, 1995; Gilmore, 2004), it is believed that videotaped materials simulate and authenticate real life situations and bring the closest approximation of real life situations to the classroom environment (Birjandi \& Derakhshan, 2014; Stempleski \& Tomalin, 1990).

\section{Learning Implicatures: Challenges and Dilemmas Facing EFL/ESL Learners and Teachers}

From cognitive-psychological and socio-psychological perspectives, interlanguage pragmatics research has investigated how factors such as input, noticing and understanding, L2 proficiency, transfer, and individual differences affect ILP development in general and implicature learning in particular. When teachers are faced with the task of teaching second or foreign language to EFL/ESL learners, one of the fundamental decisions to be made is related to the type of input, the amount, and the time it should be provided. As to the first factor, it is postulated that the classroom context is limited compared to spontaneous flow of interaction outside the classroom and naturalistic contexts in terms of learners' opportunities to authentically take on different conversational roles in a wide array of situations and engage with a range of fluent competent speakers of the language who provide them with expert input and opportunities for practice. Notwithstanding these inherent constraints, there are some other possible ways through which innovative teachers can boost the socialization experience through their teaching approaches and materials (Dufon, 2008); furthermore, drawing upon innovative approaches, teachers can make learners more aware of pragmalinguistic and sociopragmatic features (Bialystok, 1993; Kasper, 2001; Kasper \& Rose, 1999; Nikula, 2008; Thomas, 1983).

There is a general consensus that learning a language means learning not only the morphology, phonology, syntax, semantics, but also pragmatics, i.e. learning how to appropriately draw on language sociopragmatically and pragmalinguistically under different circumstances, being influenced by a number of extra-linguistic contextual factors such as social status of the speakers, social and psychological distance, and degree of imposition or power. This kind of pragmatic language use capitalizes on areas such as deixis, conversational implicature, presupposition, and speech acts. However, due to some constrains imposed on teachers and learners, teaching pragmatic language use one aspect of which is implicature makes great challenges and dilemmas for students and teachers.

Washburn (2001) enumerates the pragmatic language learning problems facing EFL/ESL learners as follows:

a. The lack of varied, naturally occurring input in both EFL and ESL contexts;

b. a lack of salience in the available input;

c. a lack of awareness about the forms, norms, and limits; and

d. a lack of direct or explicit feedback about violations of the norms in natural contexts or in textbook models.

Given the importance of the challenges students encounter, Dufon (2002) mentions that although naturalistic interactions with native speakers cater a beneficial means for learners to gain input and practice, there are some criticisms leveled against them. First, due to the scarcity of native speakers, naturalistic input is not always accessible outside the classroom, particularly in foreign language contexts. Second, even when naturalistic input is available, certain pragmatic features may not be adequately salient for learners to be noticed (Schmidt, 1993; Washburn, 2001). Third, native speakers are unlikely to provide learners with feedback on certain types of pragmatic violations, particularly those that are regarded to be social rather than linguistic (DuFon, 2002), and learners may be more sensitive to the correction of pragmatic errors that seem to reflect more upon their knowledge of the world than on their knowledge of the second language (Thomas, 1983).

It should be emphasized that teachers are the agents of change, so the responsibility of teaching pragmatic aspects of language such as the comprehension and use of implicatures falls on teachers and instruction. However, as language 
teachers, we face certain dilemmas and challenges (Washburn, 2001; Eslami-Rasekh, 2005). We lack adequate materials and training, which are hinged upon a lack of emphasis on pragmatic issues in ESL/EFL teaching methodology courses. Moreover, oftentimes little or no consistent attention is paid to pragmatic language use because it is regarded as subsidiary course content in other learning contexts. Gilmore (2004), contrasting the discourse features of seven dialogues with comparable authentic interactions, finds out that textbook dialogues differ significantly from their authentic counterparts across a range of discourse aspects including length and turn taking patterns, lexical density, false starts and repetitions, pausing, use of hesitation devices, and back-channeling.

Providing learners with rich and contextually appropriate input has been considered as a necessary condition to enhance learners' pragmatic ability when understanding and performing speech acts and implicatures in the target language (Bardovi-Harlig, 2002; Kasper, 2001, Kasper \& Roever, 2002; Martínez-Flor \& Usó-Juan, 2010a; Rose, 2005). Therefore, the context in which a language is learned seems to play an indispensable role in terms of both the quantity and quality of input to which learners are exposed (Barron, 2003). Learners in the second language community have more opportunities to come into contact with the target language, so exposure to it can improve their pragmatic ability (Martínez-Flor \& Usó-Juan, 2010b). Conversely, learners in a foreign language context are in a disadvantageous environment, since they depend exclusively on the input that arises in the classroom (Kasper \& Roever, 2002). LoCastro (2003) points out that learners are generally exposed to three types of input in EFL contexts, namely those of the teacher, the materials, and other learners. With regard to the materials and resources used to develop learners' ability to perform different speech acts, research has mainly focused on written input (i.e. textbooks) and audiovisual input (i.e. TV and films).

\section{Implicatures and the Advantages of Video-driven Prompts as Influential Sources of Input}

As a consequence of the constraints and challenges involved in dealing with teaching sociopragmatic and pragmalinguistic features in the foreign language context mentioned above, the use of authentic audiovisual and video enhanced materials and the role of instruction have gained considerable attention in the development of pragmatics and comprehension of implicatures. In fact, video input has long been regarded as an irreplaceable resource that facilitates the language learning process in the classroom setting since it provides learners with realistic models to imitate and enhance their audio-visual perceptions (Sherman, 2003). Canning-Wilson (2000) states that video brings a contextualized view of language to the classroom which in turn helps learners visualize words and meanings as well as norms and conventions for appropriate language use. Consequently, the implementation of video can be considered as an alternative source to present pragmatic features in the classroom (Rose, 1994, 1997, 1999, 2001). From this vantage point, research has been undertaken to lend support to the fact that authentic audiovisual input provides ample opportunities to present learners with different aspects of language use in various social and cultural contexts (Alcón, 2005; Fernández-Guerra, 2008; Martı'nez-Flor, 2007; Rose, 1994, 1997, 1999, 2001; Stempleski \& Tomalin, 1990; Swaffar \& Vlatten, 1997).

Grant and Starks (2001), Alcón (2005), and Martı'nez-Flor (2007) believe that authentic audiovisual input caters for abundant opportunities to address all aspects of language use in a variety of contexts. In like manner, Koike (1995) proposes that video prompts have the potentiality to contextualize language that may be misunderstood based on the linguistic code alone due to L1 transfer. Lonergan (1984) cogently emphasizes that video presents "complete communicative situations" to learners where relationships between speakers and hearers are readily apparent and the context of the interaction (e.g., home, business, etc.) is clear. Similarly, Swaffar and Vlatten (1997) note that authentic FL videos can visualize different kinds of registers and cultural contexts to learners. They also conclude that videos provide visual cues along with auditory material that improve both comprehension and learning of the content presented.

Lo"rscher and Schulze (1988) explicate that in EFL contexts the range of speech acts and realization strategies is marginalized, and that the typical interaction patterns, i.e. IRF, impose inherent limitations on pragmatic input and opportunities for practicing discourse organization strategies. Alternatively, Crandall and Basturkmen (2004) stipulate that textbook conversations do not cater sufficient pragmatic input. In a similar vein, a solid body of research findings documents that textbook conversations are not a reliable source of pragmatic input (Bardovi-Harlig et al., 1991; Boxer \& Pickering, 1995; Gilmore, 2004).

Stempleski and Tomalin (1990) also expound that videotaped materials enjoy a lot of merits. They expose students to variation in the medium of classroom materials. They also simulate and authenticate real life situations and bring the closest approximation of real life situations to the classroom environment. Hence, they not only add interest to the lessons but also increase motivation (Fluitt Dupuy, 2001). Quite on a par with others, Dufon (2002), further, explicates that videotaped materials in classroom instruction have some advantages over other means of input such as naturalistic interactions and textbooks.

Bardovi-Harlig (1999), in a seminal article, elaborating upon expanding elicitation tasks to accommodate acquisition studies, cogently argues that if we want to broaden our interlanguage pragmatics studies to include acquisition as part of the research agenda following Kasper and Schmidt (1996), we ought to involve learners at all levels, especially at the lower levels. She succinctly states that including lower-level learners will require some modifications to standard elicitation practices in order to make them more accessible. Visually oriented tasks such as presenting scenarios on video or the use of printed cartoons (Rose, 1994) have become more important because lower-level learners can interpret them more easily than the common written presentation (Bardovi-Harlig, 1999). Kasper (1997) cogently argues that "one way to overcome the inherent limitations of a FL environment is through the use of television and film, which represent rich sources of data on language use and should be fully exploited in teacher education" (P. 134). 
More recently, Jernigan (2012) investigates the effectiveness of an output-focused instructional treatment featuring video vignettes in an intensive English program setting. The results of her study support the previous research on the effectiveness of instruction on pragmatic development of learners' performance on the perception-oriented pragmatic acceptability judgment test. However, the results of the written DCT pinpointing learners' ability to express acceptable pragmalinguistic forms were less clear. Although a relatively large effect size was observed for the group receiving the output instruction, no significant effects were identified. In line with Jernigan's perception-oriented acceptability test, the present research lends support to the previously done bodies of research on the amenability of pragmatic instruction.

\section{Pedagogical Implications and Concluding Remarks}

In a nutshell, it can be concluded that videotapes have some merits over textbooks. One problem with textbooks is that the language used in them is often decontextualized, and even when it is contextualized it frequently diverges from the language used in comparable naturalistic interactions (Bardovi-Harlig et al., 1991; Boxer \&Pickering, 1995; Myers Scotten \& Bernsten, 1988). Conversely, videotapes offer more contextual information in a more efficient manner than do textbooks. They provide learners with a more complete image of the interlocutors and the setting, as well as information about posture, gestures, clothing and proxemics, all of which lead to politeness in interactions (Gass \& Houck, 1999; Stempleksi \& Tomalin, 1990). Those learners who have never had any experience of the target culture and whose familiarity with it is limited can really take advantage of these features (Dufon, 2002). In addition, with video the learners can hear paralinguistic features such as loudness, stress and intonation, all of which carry pragmatic and affective information (Washburn, 2001). Moreover, because of these extralinguistic and paralinguistic cues, videotapes can bolster learners' comprehension of the discourse (Stempleski \& Tomalin, 1990). Furthermore, when the videotapes display naturalistic interactions, they allow learners to hear authentic language.

In terms of pedagogy and curriculum development, we suggest that there should be a strong need to improve ILP abilities on the part of the learners and that the inclusion of pragmatics materials especially video-driven clips in curricula and learning materials is beneficial. Language materials developers should incorporate a variety of real life activities and learning tasks with regard to different implicatures. If conversational implicature is indeed a prevalent feature of the daily talk-in-interaction of native speakers, it seems to follow that the inclusion of its instruction to EFL learners would be logical and highly recommended. In terms of teaching implicatures, it is suggested that idiosyncratic implicatures could be introduced sooner because they are easier to comprehend (Armstrong, 2007). As an additional activity, learners could compare the conventional expressions cross-linguistically with their L1. When teaching less conventional implicatures, classroom teachers can draw on listening materials extracted from movies and TV dramas. When practicing comprehension of less conventional implicatures, teachers could motivate learners to use contextual information such as background information, and paralinguistic cues, including intonation, tone of voice, pause, gestures, facial expressions to derive meaning better (Derakhshan, 2014).

Most of our textbooks are replete with audio-materials as a listening section or conversation, a strand of research is to compare the relative effectiveness of audio versus video prompts on the comprehension and production of implicatures. Another strand of research is to find out the correlation between implicature knowledge, routines, and speech acts. Moreover, the relationship between formulaic-based implicature and idiosyncratic implicature is still unclear and underrepresented, so more studies are needed to bridge this gap. Alternatively, it is claimed that there is a positive correlation between level of proficiency and implicature knowledge (Bouton, 1994a, Taguchi, 2002, 2005, 2011); therefore, more studies are needed to delve deeply into the interrelationship between the two.

\section{References}

Alcón, E. (2005). Does instruction work for pragmatic learning in EFL contexts? System, 33 (3), 417-435.

Armstrong, S. J. (2007). Grice's cooperative principle at work in an ESL classroom: A case for teaching implicature. Journal of Inquiry and Research, 86, 77-95.

Bardovi-Harlig, K. (1999). Exploring the interlanguage of interlanguage pragmatics: A research agenda for acquisitional pragmatics. Language Learning, 49, 677-713.

Bardovi-Harlig, K. (2002). Pragmatics and second language acquisition. In R. B. Kaplan (Ed.), The Oxford handbook of applied linguistics (pp. 182-192). Oxford: Oxford University Press.

Bardovi-Harlig, K., Hartford, B.A.S., Mahan-Taylor, R., Morgan, M.J., \& Reynolds, D.W. (1991). Developing pragmatic awareness: Closing the conversation. ELT Journal, 45, 4-15.

Barron, A. (2003). Acquisition in interlanguage pragmatics: Learning how to do things with words in a study abroad context. Amsterdam: John Benjamins.

Bialystok, E. (1993). Symbolic representation and attentional control in pragmatic competence. In G. Kasper \& S. Blum-Kulka (Eds.), Interlanguage pragmatics (pp. 43-57). Oxford: Oxford University Press.

Birjandi, P., \& Derakhshan, A. (2014). Pragmatic comprehension of apology, request, and refusal: An investigation on the effect of consciousness-raising video-driven prompts. Applied Research on English Language, 3(1), 67-85.

Bouton, L. F. (1988). A cross-cultural study of ability to interpret implicatures in English. World Englishes, 7(2), 183196.

Bouton, L. F. (1994a). Can non-native speakers' skill in interpreting implicature in American English be improved 
through explicit instruction? A pilot study. In L. F. Bouton (Ed.), Pragmatics and language learning (Vol. 5, pp. 88-109). Urbana-Champaign, IL: University of Illinois, Division of English as an International Language.

Bouton, L. F. (1994b). Conversational implicature in a second language learned slowly when not deliberately taught. Journal of Pragmatics, 22(2), 157-167.

Bouton, L. (1999). Developing nonnative speaker skills in interpreting conversational implicatures in English. In E. Hinkel (Ed.), Culture in second language teaching and learning (pp. 47-70). Cambridge: Cambridge University Press.

Boxer, D., \& Pickering, L. (1995). Problems in the presentation of speech acts in ELT materials: The case of complaints. ELT Journal, 49, 44-58.

Canning-Wilson, C. (2000). Practical aspects of using video in the foreign language classroom. The Internet TESL Journal, 6, 11.

Crandall, E., \& Basturkmen, H. (2004). Evaluating pragmatics-focused materials. ELT Journal, 58 (1), 38- 49.

Derakhshan, A. (2014). The effect of consciousness-raising video-driven prompts on the comprehension of implicatures and speech acts. Unpublished PhD dissertation. Allameh Tabataba'i University, Tehran, Iran.

DuFon, M. A. (2002). Video recording in ethnographic SLA research: Some issues of validity in data collection. Language Learning and Technology, 6(1), 40-59.

DuFon, M. A. (2008). Language socialization theory and the acquisition of pragmatics in the foreign language classroom. In E. Alcón \& A. Martı'nez-Flor (Eds.), Investigating pragmatics in foreign language learning, teaching and testing (pp. 25-44). Great Britain: Cromwell Press Ltd.

Eslami-Rasekh, Z. (2005). Raising the pragmatic awareness of language learners. ELT Journal, 59 (2), 199-208.

Fernández-Guerra, A. (2008). Requests in TV series and in naturally occurring discourse: A comparison. In E. Alcón (Ed.), Learning how to request in an instructed language learning context (pp. 111-126). Bern: Peter Lang.

Fluitt-Dupuy, J. (2001). Teaching argumentative writing through film. TESOL Journal, 10(4), 10-15.

Garcia, P. (2004). Pragmatic comprehension of high and low level language learners. TESL-EJ, 8(2), 1-15.

Gass, S., \& Houck, N. (1999). Interlanguage refusals: A cross-cultural study of Japanese-English. New York: Mount De Gruter.

Gilmore, A. (2004). A comparison of textbooks and authentic interactions. ELT Journal, 58, 362-374.

Grant, L., \& Starks, D. (2001). Screening appropriate teaching materials. Closings from textbooks and television soap operas. International Review of Applied Linguistics, 39, 39-50.

Grice, H.P. (1975). Logic and conversation. In P. Cole \& J.L. Morgan (Eds.), Speech acts (pp. 41-58). New York: Academic Press.

Grice, H. P. (1989). Studies in the way of words. Cambridge, MA: Harvard University Press.

Jernigan, J. E. (2012). Output and English as a second language pragmatic development: The effectiveness of outputfocused video-based instruction. Canadian ELT Journal, 5(4), 2-14.

Kasper, G. (1997). Can Pragmatic Competence Be Taught? Retrieved from Network \#6: http://www. 1ll.hawaii.edu /sltcc/F97NewsLetter/Pubs.htm)

Kasper, G. (2001). Classroom research on interlanguage pragmatics. In K.R. Rose \& G. Kasper (Eds.), Pragmatics in language teaching (pp. 33-60). New York: Cambridge University Press.

Kasper, G., \& Roever, C. (2002). Pragmatics in second language learning. In E. Hinkel (Ed.), Handbook of research in second language teaching and learning (pp. 317-334). Mahwah: Lawrence Erlbaum Publishing.

Kasper, G., \& Rose, R. (1999). Pragmatics and SLA. Annual Review of Applied Linguistics, 19, 81-104.

Kasper, G., \& Rose, K.R. (2002). Pragmatic development in a second language. Malden: Blackwell Publishers.

Kasper, G., \& Schmidt, R. (1996). Developmental issues in interlanguage pragmatics. Studies in Second Language Acquisition, 18, 149-169.

Koike, D. (1995). Transfer of pragmatic competence and suggestions in Spanish foreign language learning. In S. Gass \& J. Neu (Eds.), Speech acts across cultures (pp.257-281). Berlin: Mouton de Gruyter.

Kubota, M. (1995). Teachability of conversational implicature to Japanese EFL learners. The Institute for Research in Language Teaching Bulletin, 9, 35-67.

Lee, J. S. (2002). Interpreting conversational implicatures: A study of Korean learners of English. The Korea TESOL Journal, 5(1), 1-26.

Levinson, S.C. (1983). Pragmatics. Cambridge: Cambridge University Press.

LoCastro, V. (2003). An Introduction to pragmatics: Social action for language teachers. Michigan: Michigan Press.

Lonergan, J. (1984). Video in language teaching. Cambridge: Cambridge University Press.

Lo"rscher, W., \& Schulze, R. (1988). On polite speaking and foreign language classroom discourse. International Review of Applied Linguistics in Language Teaching, 26, 183-199. 
Martı'nez-Flor, A. (2007). Analyzing request modification devices in films: Implications for pragmatic learning in instructed foreign language contexts. In E. Alcón \& M.P. Safont (Eds.), Intercultural language use and language learning (pp. 245-280). Amsterdam: Springer.

Martínez Flor, A., \& Usó Juan, E. (2010a). Pragmatics and speech act performance. In A. Martínez-Flor \& E. UsóJuan (Eds.), Speech act performance: Theoretical, empirical and methodological issues (pp. 3-20). Amsterdam: John Benjamins.

Martínez Flor, A., \& Usó Juan, E. (2010b).The teaching of speech acts in second and foreign language instructional contexts. In A. Trosborg (Ed.), Pragmatics across languages and cultures (pp. 423-442). Berlin: Mouton de Gruyter.

Myers Scotten, C., \& Bernsten, J. (1988). Natural conversations as a model for textbook dialog. Applied Linguistics, 9 , 372-384.

Nikula, T. (2008). Learning pragmatics in content-based classrooms. In E. Alcón, \& A. Martı'nez-Flor, (Eds.), Investigating pragmatics in foreign language learning, teaching and testing (pp. 94-113). Great Britain: Cromwell Press Ltd.

Roever, C. (2005). Testing ESL pragmatics: Development and validation of a web-based assessment battery. Frankfurt am Man: Peter Lang.

Rose, K. R. (1994). Pragmatic consciousness-raising in an EFL context. In L.F. Bouton \& Kachru, Y. (Eds.), Pragmatics and language learning (Vol. 5, pp. 52-63). Urbana, IL: University of Illinois at Urbana-Champaign.

Rose, K. R. (1997). Pragmatics in the classroom: Theoretical concerns and practical possibilities. In L. F. Bouton (Ed.), Pragmatics and language learning (Vlo. 8, pp. 267-295). Urbana, Illionis: University of Illinois at UrbanaChampaign.

Rose, K.R. (1999). Teachers and students learning about requests in Hong Kong. In E. Hinkel (Ed.), Culture in second language teaching and learning (pp. 167-180). Cambridge: Cambridge University Press.

Rose, K. R. (2001). Compliments and compliment responses in film: Implications for pragmatics research and language teaching. International Review of Applied Linguistics, 39, 309-326.

Rose, K.R. (2005). On the effect of instruction in second language pragmatics. System, 33 (3), 385-399.

Schmidt, R. (1993). Consciousness, learning and interlanguage pragmatics. In . Kasper \& S. Blum-Kulka (Eds.) Interlanguage pragmatics (pp. 21-42). New York: Oxford University Press.

Sherman, J. (2003). Using authentic video in the language classroom. Cambridge: Cambridge University Press.

Stempleski, S., \& Tomalin, B. (1990). Video in action: Recipes for using video in language teaching. New York: Prentice-Hall.

Swaffar, J., \& Vlatten, A. (1997). A sequential model for video viewing in the foreign language curriculum. Modern Language Journal, 81, 175-188.

Taguchi, N. (2002). An application of Relevance Theory to the analysis of L2 interpretation processes: The comprehension of indirect replies. International Review of Applied Linguistics, 40, 151-176.

Taguchi, N. (2005). Comprehending implied meaning in English as a foreign language. Modern Language Journal, 89, $543-562$.

Taguchi, N. (2009). Comprehension of indirect opinions and refusals in L2 Japanese. In N. Taguchi (Ed.), Pragmatic competence (pp. 249-274). New York: Mouton de Gruyter.

Taguchi, N. (2011). The effect of L2 proficiency and study-abroad experience in pragmatic comprehension. Language Learning, 61, 904-939.

Thomas, J. (1983). Cross-cultural pragmatic failure. Applied Linguistics, 4 (2), 91-112.

Washburn, G. N. (2001). Using situation comedies for pragmatics language teaching and learning. TESOL Journal, 10(4), 21-26.

Watts, R. J. (2003). Politeness. Cambridge: Cambridge University Press. 